\title{
An Early Look at Dissolution Testing, Including Equipment, Calibration, and Acceptance Criteria
}

\author{
Lee Timothy Grady \\ Vice President and Director Emeritus, United States Pharmacopeia
}

This article will give some anecdotal and factual accounts of early equipment, some discussion of calibration, and an explanation of the dissolution acceptance criteria. A good overview of the very early days of dissolution testing can be found in the book titled Pharmaceutical Dissolution Testing (1).

\section{EARLY EQUIPMENT}

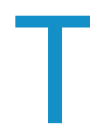

he USP-NF Joint Panel on Physiological Availability was set up in 1967 under Rudolph Blythe who already had led industrial attempts at standardization of drug release tests. The testing of a single unit dose was promoted because there was the practical consideration of multiple dosage units impacting each other during testing if a number of them were placed in the same flask. That concern of course would be diminished where agitation conditions were gentle, but there were no examples available. Thus, the joint panel in late 1968 directed William J. Mader at the Drug Standards Laboratory (DSL) to do unit testing. (DSL was funded jointly by the APhA Foundation, to which it belonged, the American Medical Association, and USP). That effort led to adoption, in 1970, of an official apparatus, the rotating basket, derived from one designed by the late Prof. M. Pernarowski, long an active force in pharmaceutical science in Canada. Hannah Klein was the DSL bench chemist, and it was her drawing of the rotating basket apparatus that appeared in the 1970 compendia.

Mr. Mader constructed a 100-gallon, glass-walled water bath with a 1-in. HDPE polymeric cover into which six holes were cut. He had contacted a supplier of the sort of aquariums found in bars and lobbies (and my brother's basement eventually). The bath was installed in 1968, probably early or mid-summer, in DSL on the lower level of the headquarters of APhA on Constitution Avenue. The glass vessels allowed observation of the behavior of the test specimen during the test, a critical feature. He also initiated work with Bill Hanson from California who had made the NF rotating bottle apparatus that had been used by Rudolph Blythe in testing of extended-release capsules (Spansules) when he was with SKF. Hanson obliged by designing a six-station testing head that was driven by a single motor, thereby solving the problem of synchronizing multiple motors. Also, belt- or chain-driven shafts didn't transmit motor vibration. That apparatus was workable in quality control laboratory environments.

As for the vessel design, Pernarowski's work was with a three-neck, round-bottom flask. I believe the speed of rotation at $100 \mathrm{rpm}$ was suggested by him, but the apparatus was chosen by the USP Panel partly because a variety of rotation rates could be used (but weren't). When the project was taken up by Mader, he brought industrial chemistry experience to the table. Such flasks required cork rings and had higher breakage rates. So he selected a rugged reaction kettle that was commonly in use in the chemical synthesis industry. (That would have been the right choice for the paddle apparatus.)

As more laboratories entered the field, and experiences and mistakes accumulated, the period 1970-1980 was one of official test and equipment refinement. Later, a second apparatus was based on Poole's use of available organic synthesis round-bottom flasks as refined by the St. Louis laboratory. Both choices of flasks proved not to be optimal, indeed, better if the two had been reversed. Eventually USP would offer seven apparatus, three for transdermal articles alone. A flow-through cell and a reciprocating cylinder were adopted by way of harmonization with the European Pharmacopoeia.

Formulations available in the late 1960 s typically did not disintegrate rapidly; rather disintegration times of 10-20 min were commonplace, and starch was the dominant disintegrant. Basket mesh gauge was selected to retain those granulations of the day, but the finer powders were able to sink to the bottom of the kettle where there was minimal mixing caused by the basket. Reverting later on to the round-bottom flask achieved better mixing of powders below the basket. DSL observed mixing patterns by pressing food dye powder in the infrared press to make test tablets. On the other hand, John Poole at Wyeth used a paddle in a roundbottom flask-Prof. John Wagner influenced the FDA St. Louis laboratory to use that with the paddle apparatus at $50 \mathrm{rpm}$. That laboratory did not have anyone on the staff with pharmaceutical product development or control experience. Their paddle apparatus had to be redesigned from the metal-sided heating bath they used, which prevented observation of the disintegration characteristics of the test specimen. It turned out that the reaction kettle would have been better for mixing powders from rapidly disintegrating dosage forms or for increasing the paddle rotation to 60 or $75 \mathrm{rpm}$.

The glass bath was critical to observing ongoing disintegration, which was the key issue for formula- 
tions of the day. Many tablets took more than 30 min to disintegrate without discs in the test apparatus because of strong compression for pharmaceutical elegance and sugar-coatings. Bath circulator pumps and other equipment on the same bench were a major source of vibration, and in one case, proximity of a lab to an elevator shaft in a wooden-floor building. We told people that if a 4-place balance couldn't be calibrated thereon, the bench was unacceptable.

\section{CONTEXT OF THE PROJECT}

I had started at the lab on October 1, 1968, just in time to attend the closing meetings of the USP-NF Joint Panel on Physiological Availability. My work at Merck Institute had included what was then known as physiological availability, but that was still in the Pharmacology-Toxicology Department. Nevertheless, Mader called me into his office the Monday after those meetings-he asked which parts of the DSL workload I would prefer to supervise. Being new, I asked for his ideas. He said, "I will do the dissolution rush project, and you do everything else (method development and vetting and reference standard evaluations) - you are too young to have your career ruined." You see, it was already painfully obvious that dissolution testing would undercut the brand/generic performance posturing. Some major manufacturers bemoaned the onset of official standards. Others cooperated. I did not take control of the project until about 1973 when Bill went to Alza. In 1975, staff responsibility for new USP Subcommittee 9 was assigned to me and my lab. The prodigious worker Prof. Tom Medwick was elected as Chair, so all the stops came out. Dr. Jane Sheridan at HLaR followed on, energetically, as did Jordan Cohen. Policies and requirements poured out.

One now amusing anecdote is that around 1969-1970, DSL hired a new Ph.D., Don Hong, from the University of Michigan. His parents had the off-campus Chinese restaurant there. The night before his starting day, the thermostat failed allowing the water to melt the caulking-100 gallons of water on the concrete floor. When Dr. Hong appeared at the appointed time, 9 a.m., he was handed the mop as his first PhD project! He, Bob King, and I took turns. Note: Following the sale of DSL and NF to USP in 1974, Don and his wife moved to Sterling in Rensselaer NY where they served me the best Chinese meal I ever had, anywhere.

\section{DATA VARIABILITY \\ Calibrator Tablets}

Tablets and capsules available in the 1980s often showed $10-20 \%$ relative standard deviation in amounts dissolved, most obviously, though, for slow-dissolving drugs as shown by the FDA St. Louis laboratory's testing of about 200 different batches of available drugs.

However, to have enforceability, the key problem in dissolution testing was lab-to-lab disagreement. In 1978 two calibrator tablets were instated by the compendia, Salicylic Acid (325 mg) and Prednisone $(50 \mathrm{mg}$ ) tablets. The former was single ingredient, the latter an unmarketed commercial formulation. Every calibrator batch was subjected to a PMA/PhRMA collaborative study to determine acceptance statistics. Recall that the compendial mindset was on System Suitability Tests. Calibrators were adopted primarily to pick up vibration in the equipment, failures in the drive chains and belts, and operator error. Wherever perturbations are introduced in USP equipment, one of the calibrators always picks them up. They were not adopted to test either deaeration or temperature control, but that was the actual experience. The instruction at that time was to "deaerate," but how was not specified. In the earliest days in the Drug Research and Testing Lab (DRTL, a renamed $D S L$ ), the method of deaeration was boiling the deionized water. A little precarious. At present, heat and vacuum are favored (2). There was constant interest and many literature reports about calibrators and deaeration between 1994 and 1999. The number of tests to qualify an apparatus was halved in the late 1990s as the method had achieved a testing tradition. Eventually Salicylic Acid Tablets were dropped, but those at the start solved the urgent problem of many competing apparatus proposals, all said to offer "gentle" conditions (Not!) and also temperature controls.

\section{Acceptance Criteria}

USP over time changed its decision rules. The requirements went from individual unit results needing to pass within the range to today, where a geometric mean and $\mathrm{CV}$ are the criteria. Yet even today, laboratories can fail, especially on the international scene. I ran an international collaborative study for FIP or the APhA Academy of Pharmaceutical Scientists in the late 1970s with shocking results. There was not yet a test tradition for this analysis.

Batch property analyses of strength use an assay of a composite of 20 dosage units precisely to exclude unit variation from the assay. The content of individual dosage units was tested as content uniformity. Patients swallow single units. Dissolution testing always used mixed decision rules. Decisions on dosage unit values proved to be unsatisfactory as an official requirement because it caused lab-to-lab numerical discrepancies. In 1977 USP required averaging the values of units, thereby subtly moving toward the concept of dissolution as a batch characteristic.

Mader was experienced in the use of statistics in quality control. From the beginning, he wanted a test procedure that used multiples of six units. He explained his choice of six units by showing me a table of Student's $t$-statistic values, which graphically can be seen to level off beyond the value for six units. Doubling the number to 12 by adding a second test stage only tightens the $95 \%$ confidence limits by a relative $11 \%$. (Note: I knew a control director who 
would not sign off on even small changes in formulations or suppliers without dissolution experiments based on 30 units, either in product development or manufacture.) The two-stage test appeared in 1975 in the first official general chapters. Recall that it judged individual values. The test was rooted in the wide adoption of sequential testing in the world of quality control. However, USP and NF specifications differed: the interpretation in the National Formulary called for a minimum amount dissolved at a specified time whereas the United States Pharmacopeia called for a minimum amount of time for a specific amount to be dissolved. The latter was over the objection by Mader because he said that the latter was a testing burden on control laboratories.

\section{Chemists versus Pharmacologists}

The general chapter at that time required 10 of 12 units to pass at stage two. I have already discussed the need not to base the joint panel decision rule on individual tablet data because of the interlaboratory variance of at least $3 \%$ even for precision official methods of the day, as demonstrated by a range of AOAC collaborative studies. UCSF Prof. Sid Riegelman, a fixture in pharmaceutics, made much of that so the whole dissolution project was at risk, saved by the new, determined USP Subcommittee 9 .

A frequent question: what does the general chapter value " $Q$ " stand for? $Q$ stands for the quantity dissolved as a percent of label. Very imaginative. The nature of this acceptance value is that of a floor, not a ceiling or a target. Acceptance values are inherent in sequential sampling-a strict first stage results in reduced testing load and is chosen based on critical product characteristics and known variability of the manufacturing process.

\section{AT THE END OF THE DAY}

A surprise came for everybody who said in the mid1970s that there could be 100 formulation factors that might affect bioavailability or bioequivalence. Well, 100 never showed up. What did show up constantly was hydrophobic magnesium stearate as a lubricant, and it is still a problem with older formulations. What also showed up were sugarcoated tablets because of a hydrophobic shellac subcoat. Products then were shellac-coated both for elegance and for longer shelf life.

Everybody already knew that inadequate disintegration was a problem, a natural tension against elegance. Disintegrant integrity and force of compression are operational here. Superdisintegrants obviate that problem. Particle size of lower solubility drugs also was most obvious to all. The pharmaceutics were settled a generation ago.

All four of these proven nonequivalence factors are sensitive to dissolution testing. Wherever there was a medically significant problem, a dissolution test always showed the difference between the nonequivalent formulations, and that still holds true today.

When I was in another country that imported medicines, an official told me that the two most critical tests of quality to protect that public were dissolution and sterility, identity and strength having been established.

\section{REFERENCES}

1. Krämer, J.; Grady, L. T.; Gajendran, J. Historical Development of Dissolution Testing. In Pharmaceutical Dissolution Testing. Dressman, J. B., Krämer, J., Eds.; Taylor \& Francis: New York, 2005.

2. $\quad<711>$ Dissolution. In The United States Pharmacopeia and National Formulary USP 37-NF 32; The United States Pharmacopeial Convention, Inc.: Rockville, MD, 2014. 